\title{
Adrenal gland modulates oestrogen requirement for implantation in the rat
}

\author{
S. K. Dey and D. C. Johnson \\ Departments of Gynecology \& Obstetrics and Physiology, Ralph L. Smith Research Center, \\ University of Kansas Medical Center, Kansas City, Kansas 66103, U.S.A.
}

\begin{abstract}
Summary. The effect of adrenal steroids upon implantation was evaluated by examining the efficacy of oestradiol-17 $\beta$ on the initiation of implantation in ovariectomized, ovariectomized plus adrenalectomized or hypophysectomized pregnant rats treated with progesterone. More oestrogen $(\times 5)$ was required in ovariectomized animals to obtain results equivalent to those obtained with the other animal models.
\end{abstract}

\section{Introduction}

In the rat, maternal oestrogen is an absolute requirement for implantation in a progesteroneprimed uterus. In the absence of oestrogen the blastocysts become dormant but remain viable for several days; i.e. a state of delayed implantation is established (Mayer, 1963). A single injection of oestrogen, however, will promptly induce implantation of these embryos. Delayed implantation can be achieved in the rat by removal of the pituitary or the ovaries before the presumed 'oestrogen surge' during the preimplantation period and maintaining the animals on progesterone (Shelesnyak $\&$ Kraicer, 1963). These two procedures do not appear to produce the same effect because different thresholds of oestrogen needed for implantation have been reported (Brandon \& Raval, 1979; Johnson \& Dey, 1980); more oestrogen is required to induce implantation in ovariectomized than in hypophysectomized 'delayed-implanting' rats. Although the reason for the differential has not been addressed, it is possible that adrenal corticoids could be a factor in the ovariectomized females. To test this idea, various doses of oestradiol were used to induce implantation in 'delayedimplanting' rats produced by ovariectomy, hypophysectomy or a combination of ovariectomy and adrenalectomy.

\section{Materials and Methods}

\footnotetext{
Virgin female rats (Holtzman strain) weighing 250-280 g were placed into groups on Day 3 of pregnancy (Day 1 = morning of finding spermatozoa in the vagina). Hypophysectomy was performed via the parapharyngeal approach using ether anaesthesia; a 5\% solution of glucose was substituted for drinking water after this operation. Ovariectomy and adrenalectomy were performed under ether anaesthesia, using a dorsolateral incision. At the time of surgery and daily thereafter the animals were injected (subcutaneously) with $2 \mathrm{mg}$ progesterone (Sigma Chemical Co, St Louis, MO) dissolved in 0.1 ml sesame seed oil. On Day 8 of pregnancy, 5 days after surgery, the animals were given a single intravenous injection of oestradiol-17 (Sigma) dissolved in saline. The crystalline oestradiol was weighed on an electrobalance (Cahn/Ventron Corp., Paramount, $\mathrm{CA}$ ) and dissolved in absolute ethanol. The desired concentration was then obtained by pipetting various amounts of the oestradiol solution into a $10 \mathrm{ml}$ volumetric flask and diluting with $0.15 \mathrm{M}-\mathrm{NaCl}$ : in no case was the concentration of ethanol greater than $0.5 \%$. At $24 \mathrm{~h}$ after the oestradiol injection the animals were lightly anaesthetized with ether and injected (i.v.) with $1 \mathrm{ml}$ of a $2 \%$ solution of Chicago Blue B dissolved in 0.15 $\mathrm{M}-\mathrm{NaCl}$. After 15-20 min, the rats were killed with an overdose of ether.

Discrete blue bands around the uterus indicated implantation sites (Psychoyos, 1973). The uteri of animals not showing sites were flushed with saline and the number of blastocysts recovered was counted. Only animals with implantation sites or blastocysts were included in the study. ?
} 
Table 1. The amount of oestradiol needed to induce implantation in 'delayedimplanting' rats maintained with progesterone

\begin{tabular}{lccccc}
\hline Surgery & $\begin{array}{c}\text { Dose of } \\
\text { oestradiol } \\
\text { (ng/rat) }\end{array}$ & $\begin{array}{c}\text { Rats with IS/ } \\
\text { no. of rats } \\
(\%)\end{array}$ & No. of IS* & $\begin{array}{c}\text { Non-implanting } \\
\text { blastocysts } \dagger\end{array}$ \\
\hline Hypophysectomy & 30 & $11 / 11(100)$ & $8 \cdot 3 \pm 1 \cdot 1$ & - \\
Ovariectomy & 30 & $0 / 7$ & $(0)$ & - & $6 \cdot 0 \pm 0 \cdot 9$ \\
& 60 & $1 / 7$ & $(14)$ & 11 & $6 \cdot 3 \pm 1 \cdot 0$ \\
& 100 & $7 / 10(70)$ & $6 \cdot 0 \pm 1 \cdot 5$ & $8 \cdot 7 \pm 3 \cdot 3$ \\
& 150 & $10 / 10(100)$ & $6 \cdot 4 \pm 1 \cdot 0$ & - \\
Ovariectomy+ & 200 & $7 / 7(100)$ & $10 \cdot 7 \pm 1 \cdot 8$ & - \\
adrenalectomy & 30 & $7 / 7(100)$ & $11 \cdot 3 \pm 0.9$ & - \\
\hline IS = implantation sites. & & & \\
*Animals with implantation sites only. \\
†Animals without implantation sites.
\end{tabular}

\section{Results}

Table 1 shows that $30 \mathrm{ng}$ oestradiol induced a full complement of implantation sites in hypophysectomized and ovariectomized + adrenalectomized 'delayed-implanting' rats. In contrast, this dose did not induce implantation in any of the animals that were only ovariectomized. In the ovariectomized females a dose of $150 \mathrm{ng}$ was required to obtain implantation in all animals. The animals in the ovariectomy-only group treated with 100 or $150 \mathrm{ng}$ oestradiol had a reduced number of sites when compared to those of the ovariectomy + adrenalectomy group. Although we consider this a function of surgical skill, it could indicate that larger doses of oestrogen were detrimental for implantation. To test this further, another group was given $200 \mathrm{ng}$ oestradiol using extra care in the surgical manipulation of the ovaries and oviducts: a full complement of sites was found in most animals.

\section{Discussion}

The present results indicated clearly that removal of adrenal function, either by hypophysectomy or adrenalectomy, reduces the amount of oestradiol needed to induce implantation in the rat. Brandon \& Raval (1979) reported that a minimum dose of $200 \mathrm{ng}$ oestradiol $/ \mathrm{kg}$ body weight (i.v.) was necessary to induce implantation in $90 \%$ of ovariectomized rats. Using the same strain of animal as that of the present study, Johnson \& Dey (1980) found that $80 \mathrm{ng} / \mathrm{kg}$ induced a full complement of implantation sites in hypophysectomized rats. The dose used in the present experiment that induced implantation in all hypophysectomized and adrenalectomized + ovariectomized animals was about $120 \mathrm{ng} / \mathrm{kg}$. Perhaps a lower dose would have accomplished implantation in a majority of animals but this was not the area of interest. The important point is that doubling the dose of oestradiol to $60 \mathrm{ng}$ (about $240 \mathrm{ng} / \mathrm{kg}$ ) induced implantation in only $14 \%$ of ovariectomized animals. A 5-fold increase in dose, to $150 \mathrm{ng}$, was required to obtain the same success in animals with adrenals as in those without them.

The question of what role the adrenal plays in the uterine response to oestrogen is difficult to answer. Because all of the animals received exogenous progesterone any effect of adrenal progesterone would seem trivial. More probable are the effects of glucocorticoids acting through specific receptors that are known to be present in the uterus (Panko et al., 1981). In a previous study we found that dexamethasone, a potent synthetic glucocorticoid, inhibited the action of oestradiol on 
implantation, but only if it was present at least $6 \mathrm{~h}$ before the oestrogen (Johnson \& Dey, 1980). Thus acute increases in adrenal steroids such as those associated with ether anaesthesia needed for the injection of oestrogen (Stern \& Voogt, 1973) would not be expected to alter the response in ovariectomized rats.

Because prostaglandins (PG), and especially PGE-2, have been implicated as important factors in initiating implantation in the rat (Kennedy, 1977; Johnson \& Dey, 1980), their relationship to adrenal function would seem most appropriate for consideration. Glucocorticoids are known to inhibit phospholipase A-2 activity and thus reduce the availability of arachidonic acid for PG synthesis (Blackwell et al., 1978; Russo-Marie et al., 1979; Pakrasi et al., 1983). Furthermore, the inhibition of oestrogen action on implantation caused by dexamethasone was reversed by administration of PGE-2 (Johnson \& Dey, 1980). The latter study also demonstrated that the inhibition could be overcome by administration of histamine, which is a stimulator of phospholipase A-2 activity (Blackwell et al., 1978). The results of the present study, added to those of our previous investigations, are therefore consistent with the view that removal of adrenal glucocorticoids in 'delayed-implanting' rats reduces the threshold for oestradiol needed for implantation by removing a modulator of PG synthesis.

Other more direct effects of glucocorticoids, for example, a reduction in oestrogen receptor number or binding affinity by adrenal steroids, could be involved in altering oestrogen action upon the uterus. Campbell (1978) reported that dexamethasone produced a reduction in the nuclear receptor-oestrogen complex in the uterus. However, we do not know whether the classical oestrogenreceptor complex is vital for the initial stages of implantation. We have reviewed some of the evidence indicating that the initiation of implantation may involve non-genomic oestrogenic actions (Dey \& Johnson, 1986). Until more information is available on the mechanism of action of oestrogen in the implantation process we cannot offer further speculations as to how adrenal steroids are involved. There is no doubt, however, that a functional pituitary-adrenal axis alters the oestrogen threshold for initiation of implantation.

This study was supported in part by a grant from the National Institute of Child Health and Human Development; HD-12304.

\section{References}

Blackwell, G.J., Flower, R.J., Nijkamp, F.P. \& Vane, J.R. (1978) Phospholipase A2 activity of guinea pig isolated perfused lungs: stimulation and inhibition by anti-inflammatory steroids. Br. J. Pharm. 62, 79-89.

Brandon, J.M. \& Raval, P.J. (1979) Interaction of estrogen and histamine during ovum implantation in the rat. Eur. J. Pharmacol. 57, 171-177.

Campbell, P.S. (1978) The mechanism of the inhibition of uterotrophic responses by acute dexamethasone pretreatment. Endocrinology 103, 716-723.

Dey, S.K. \& Johnson, D.C. (1986) Embryonic signals in pregnancy. Ann. N.Y. Acad. Sci. 476, 49-62.

Johnson, D.C. \& Dey, S.K. (1980) Role of histamine in implantation: dexamethasone inhibits estradiolinduced implantation in the rat. Biol. Reprod. 22, 1136-1141.

Kennedy, T.G. (1977) Evidence for a role for prostaglandins in the initiation of blastocyst implantation in the rat. Biol. Reprod. 16, 286-291.

Mayer, G. (1963) Delayed implantation in rats: a method of employing the mechanisms of ovo-implantation. In Delayed Implantation, pp. 213-231. Ed. A. C. Enders. University of Chicago Press, Chicago.
Pakrasi, P.L., Cheng, H.C. \& Dey, S.K. (1983) Prostaglandins in the uterus: Modulation by steroid hormones. Prostaglandins 26, 991-1009.

Panko, W.B., Clark, J.H. \& Walters, M.R. (1981) Glucocorticoid receptors: documentation in the rat uterus. J. Receptor Res. 2, 29-45.

Psychoyos, A. (1973) Endocrine control of egg implantation. In Handbook of Physiology, Section 7; Endocrinology, Vol II, pp. 187-215. Eds R. O. Greep \& E. B. Astwood. American Physiological Society, Washington, D.C.

Russo-Marie, F., Paing, M. \& Duval, D. (1979) Involvement of glucocorticoid inhibition of prostaglandin secretion. J. biol. Chem. 254, 8498-8504.

Shelesnyak, M. \& Kraicer, P.F. (1963) The role of estrogen in nidation. In Delayed Implantation, pp. 265-279. Ed. A. C. Enders. University of Chicago Press, Chicago.

Stern, J.M. \& Voogt, J.L. (1973) Comparison of plasma corticosterone and prolactin levels in cycling and lactating rats. Neuroendocrinology 13, 173-181.

Received 19 August 1986 